\title{
Risk Factors for Coronary Heart Disease in Hawaiian and Japanese Males in Hawaii ${ }^{\star}$
}

\author{
C. S. CHUNG, D. R. BASSETT, R. C. MOELLERING, Jr., G. ROSENBLATT, \\ J. STOKES, III, and H. YOSHIZAKI
}

\author{
From the School of Public Health and Pacific Biomedical Research Center, University of Hawaii, and Hawaii \\ Cardiovascular Study, The Queen's Hospital, Honolulu, Hawaii
}

Numerous studies have attempted to relate possible risk factors to coronary heart disease. The degrees of association between many presumed risk factors and the disease vary with population, type of data, and method of analysis, though there is a general agreement that serum cholesterol concentration and hypertension are strongly associated with the risk of coronary heart disease.

However, no systematic approach has been made to compare possible effects of risk factors between two or more racial groups living in a common environment. Detection of heterogeneity of the effects of risk factors might suggest possible differences in the pathogenetic process in such groups. The present study attempts to compare a set of risk factors as related to coronary heart disease between Hawaiian and Japanese males residing in Hawaii. Bennett, Tokuyama, and McBride (1962) have shown a clear-cut difference in the death rate due to cardiovascular disease in these two racial groups. Differences in the expression of risk factors, if detected, can be considered in terms of genetic and non-genetic differences between the two racial groups.

Bassett et al. (1968) have described the present data and compared a large number of variables individually between Hawaiian and Japanese subjects. The present report attempts to answer the following questions using discriminant analysis: (1) What is the most economical linear combination of risk variables which maximizes the difference between the case and control groups in Hawaiians, and in Japanese? (2) Is there any heterogeneity in the effects of the significant risk factors between the two racial groups? The advantages of the discriminant

\footnotetext{
Received June 11, 1968.
}

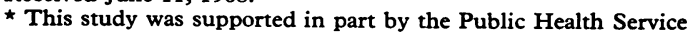
grants HE 07543 and FR 00247 from the National Institutes of Health, and by grants from the Hawaii Heart Association and the Daland Fund of the American Philosophical Society (DRB). analysis over the univariate comparison in coronary heart disease have been demonstrated (Morris et al., 1966; Truett, Cornfield, and Kannel, 1967). The practical value of the discriminant function in coronary heart disease lies in the prediction of the risk for normal population. Such an approach was also found useful in classifying unknown cases into two genetic types of muscular dystrophy when various symptoms are overlapping between the two entities (Chung and Morton, 1959).

\section{Material and Methods}

Subjects. Full description of the data has been made by Bassett et al. (1968). The 'cases' consist of Japanese and 'Hawaiian' males who experienced electrocardiographically-proven acute myocardial infarction between ages 35 and 64 in the years from 1955 to 1964 . 'Hawaiians' are defined as those individuals with $25 \%$ or more Hawaiian 'blood', whereas Japanese are represented only by unmixed individuals, with two exceptions. No persons of Hawaiian-Japanese mixture were included in the data.

The controls are also entirely males who were matched with the cases as much as possible with respect to age and race. The controls are of two types. These are 'hospital' and 'population' controls. The hospital controls are those that were in hospital within 18 months of the time of the admittance of the index cases and were free of detectable coronary heart disease before this study. The population controls are a representative sample of the general population with the restricting criteria on sex, age, and race. These controls were chosen from monthly lists of subjects examined by the State Health Department which was conducting a general health survey on the island of Oahu.

All subjects selected were interviewed, examined, and subjected to laboratory testing. The details of interviews, examinations, and kinds and methods of laboratory tests have been described by Bassett et al. (1968).

Factors Considered. The variables considered in the present study are listed in Table I. The total num59 
TABLE I

VARIABLES STUDIED IN DISCRIMINANT ANALYSIS

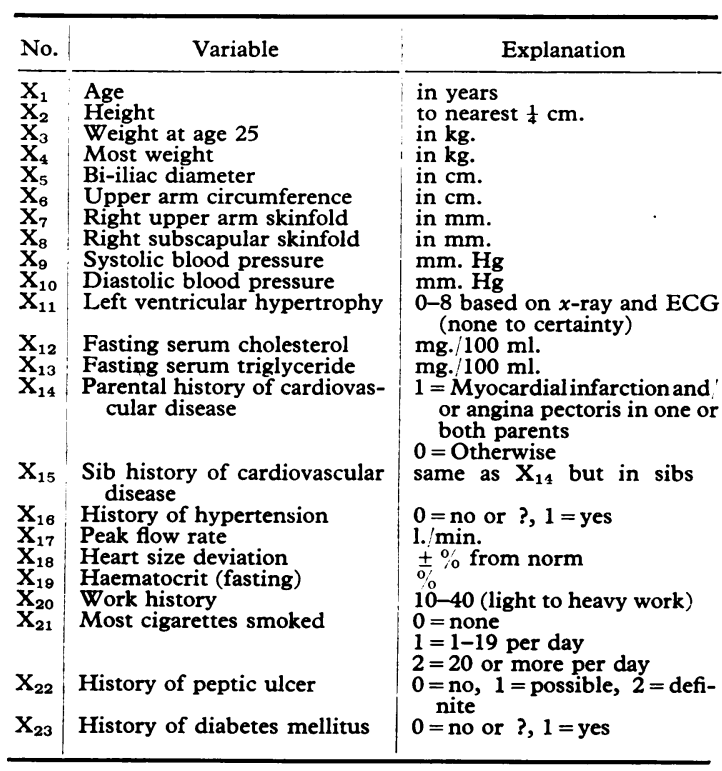

numerous than that included in this report. Selection of variables was made on the basis of availability of the information for the entire sample and possible relevance to risk in coronary heart disease. Of the 330 subjects studied by Bassett et al. (1968), 5 were excluded from this study because of missing information for one or more variables reported here.

The variables used in the analysis consist of 5 classes: (a) age $\left(\mathbf{X}_{1}\right)$, (b) anthropometric measurements $\left(\mathbf{X}_{2}-\mathbf{X}_{\mathbf{8}}\right)$, (c) cardiovascular and pulmonary characteristics $\left(\mathbf{X}_{\mathbf{9}}-\right.$ $\mathbf{X}_{19}$ ), (d) living pattern $\left(\mathbf{X}_{20}\right.$ and $\left.\mathbf{X}_{21}\right)$, and (e) history of specific diseases $\left(X_{22}\right.$ and $\left.X_{23}\right)$. The meanings of most variables investigated are self-evident. The details of techniques used for various measurements have been presented in the report by Bassett et al. (1968). However, left ventricular hypertrophy needs a further comment. A scale of 0 to 8 was devised to designate the degree of hypertrophy on the basis of $x$-ray and electrocardiogram, as shown in Table II. Instead of the pre-

TABLE II

CODES FOR LEFT

VENTRICULAR

HYPERTROPHY

\begin{tabular}{c|c|c}
\hline$X$-ray & ECG & $\begin{array}{c}\text { Numerical } \\
\text { value }\end{array}$ \\
\hline- & - & 0 \\
- & $?$ & 1 \\
$?$ & + & 2 \\
$?$ & $?$ & 3 \\
$?$ & + & 4 \\
+ & $\overline{5}$ \\
+ & $?$ & 6 \\
+ & + & 7 \\
\hline
\end{tabular}

sent weight, weight at age 25 and most weight attained were used in the analysis to maximize the predictive $\stackrel{\mathbb{D}}{\stackrel{D}{ }}$ value of the study.

Methods of Analysis. Since our basic problem is to distinguish the cases from the control group on the $\frac{C}{0}$ basis of multiple measurements, the use of discriminant $\frac{\omega}{\omega}$ function approach is a logical choice for such a situation. $\vec{\nabla}$ After Fisher (1938), we are to construct a linear function $\propto$ of a minimum set of multiple measurements that will $\&$ maximize the difference between the two groups. It $\vec{\circ}$ has been shown that computationally the discriminant function can be obtained by regressing pre-assigned $\vec{\omega}$ values constant to each group $(\mathrm{Y})$ on variables of interest (Fisher, 1938). The analysis is carried out pairwise. For example, one case group $(Y=1)$ is contrasted with its control group $(\mathrm{Y}=0)$ in one analysis. Thus, the computational method employed for the present study is multiple regression. The approach is equally applicable to discrimination of any two groups, as in the hospital controls against the population controls.

Economizing the number of variables is one of the most important considerations in any prediction formula. In order to obtain a minimum set of variables which still maximizes the difference between the case and the control groups, we have used the stepwise regression method in selecting variables. A variable was included in the selected set if the reduction in the error sum of squares due to that particular variable was significant as tested by the $F$ test proceeding from the variable that caused the largest amount of reduction. The programme on the CDC 3100 computer was developed by Dr. M. P. Mi of the Genetics Department of the University of Hawaii.

Using the method of discriminant function, we have proceeded in the following manner for analysis of our data. First the hospital controls were contrasted to the population controls within races to test the consistency of the two sources of data. Having found good comparability of the two control populations, the pooled control group was discriminated against the case group with respect to the risk variables within races.

Heterogeneity of a set of coefficients of the discriminant function (partial regression coefficients, $b_{1}$ ) was tested by the following method (see Rao, 1952). Mathematically the null hypothesis that we are testing is $b_{1}=b_{1}^{\prime}, b_{2}=b_{2}^{\prime}, b_{3}=b_{3}^{\prime} \ldots$ where $b_{1}$ and $b_{1}^{\prime}$ represent the ith coefficient for Hawaiians and Japanese, respectively. The test depends on the variance ratio obtained by $\left(R_{1}^{2}-R_{0}^{2}\right) / p$ divided by $\left.R_{0}^{2} / n+n^{\prime}-2 p-2\right)$ with $p$ and $\left(n+n^{\prime}-2 p-2\right)$ degrees of freedom, where

$\mathbf{R}_{0}^{2}=$ sum of the two residual sums of squares within Hawaiian and Japanese groups,

$R_{1}^{2}=$ residual sum of squares obtained from the 'within race' sum of squares matrix,

$\mathrm{n}=$ number of observations for Hawaiians,

$\mathbf{n}^{\prime}=$ number of observations for Japanese, and

$\mathrm{p}=$ number of parameters.

Symbolically

$R_{0}^{2}=\sum_{r}\left(Y_{r}-\bar{Y}\right)^{2}+\sum_{r}\left(Y_{r}^{\prime}-\bar{Y}^{\prime}\right)^{2}-\sum_{i}\left(b_{1} x_{1} y\right)-\sum_{1}\left(b_{1}^{\prime} x_{1}^{\prime} y^{\prime}\right)$

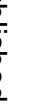


and

$$
R_{1}^{2}=\sum_{r}\left(Y_{r}-\bar{Y}\right)^{2}+\sum_{r}\left(Y_{r}^{\prime}-\bar{Y}^{\prime}\right)^{2}-\sum_{i}\left(b_{1}^{\prime \prime} x_{1}^{\prime \prime} y^{\prime \prime}\right)
$$

where $x_{1} y, x_{1}^{\prime} y^{\prime}$, and $x_{1}^{\prime \prime} y^{\prime \prime}$ are the ith elements in the vectors involving $\mathrm{Y}$ in the sum of squares matrices for Hawaiians, Japanese, and pooled 'within races', respectively, whereas $b_{i}, b_{i}^{\prime}$, and $b_{i}^{\prime \prime}$ are corresponding partial regression coefficients.

The variables whose coefficients were tested for heterogeneity include only those factors that were found significant in the stepwise regression procedure in either or both racial groups.

Logarithmic transformation was performed on the weight and height measurements to study the mutual relations between these anthropometric variables with respect to the risk of the disease, if significant, and to stabilize the variance.

\section{Results}

The discriminant analysis between the hospital and population controls within races has shown that the two control series are gratifyingly comparable in nearly all respects. On the stepwise regression, the only variables that reached the significance level were work history for the Hawaiian group, and upper arm circumference for the Japanese group. The Hawaiian hospital controls had, on the average, slightly heavier work history than the population controls, whereas the Japanese hospital controls showed somewhat larger upper arm circumference than the population controls. The respective regression coefficients are $0.0215 \pm 0.0067$ and $0.0661 \pm 0.0148$, when the hospital controls were assigned the value of 1 and the population

control the value of 0 for the $\mathrm{Y}$ variable. Since the two control series appear fairly comparable in both racial groups, the two types of controls will be pooled to form a larger control series for each race in the following analyses.

Table III shows the mean values of the factors studied for the case and pooled control groups by race. Table IV presents the results of the discriminant analyses between the case and the control groups for each race separately and for the racial groups pooled. The Table shows coefficients of the discriminant function (partial regression coefficients) of only those variables that were found significant on the stepwise regression analysis when $Y=1$ was assigned to the case group and $Y=0$ to the control group.

For both racial groups, the cases exhibited consistently higher frequencies of positive left ventricular hypertrophy and history of hypertension compared with the controls. This result indicates that each of these factors exerts a statistically independent effect on the risk of coronary heart disease. Since left ventricular hypertrophy is known to be a consequence of hypertension, the observation must mean that the two kinds of information are complementary in predicting the risk of coronary heart disease. It is possible that one can develop left ventricular hypertrophy without knowing of one's hypertension, resulting in a combination of positive left ventricular hypertrophy and negative history of hypertension. Poor memory of the patient and inaccurate measurement of hypertrophy can also effect discordant results. It should also be pointed out that the

TABLE III

MEANS OF VARIABLES FOR CASE AND CONTROL GROUPS BY RACE

\begin{tabular}{|c|c|c|c|c|c|c|}
\hline & \multicolumn{2}{|c|}{ Hawaiian } & \multicolumn{2}{|c|}{ Japanese } & \multicolumn{2}{|c|}{ All Races } \\
\hline & Case & Control & Case & Control & Case & Control \\
\hline $\begin{array}{l}\text { Age (yr.) } \\
\text { Height (cm.) } \\
\text { Weight at } 25 \text { (kg.) } \\
\text { Most weight (kg.) } \\
\text { Bi-iliac diameter (cm.) } \\
\text { Upper arm circum. (cm.) } \\
\text { Rt. u. arm skinfold (mm.) } \\
\text { Rt. subscap. skinfold (mm.) } \\
\text { Systolic B P (mm. Hg) } \\
\text { Diastolic B P (mm. Hg) } \\
\text { Left ventricular hypertrophy } \\
\text { Cholesterol (mg./100 ml.) } \\
\text { Triglyceride (mg./100 ml.) } \\
\text { Parent CV history } \\
\text { Sib CV history } \\
\text { History of hypertension } \\
\text { Peak flow rate (l./min.) } \\
\text { Heart size deviation ( } \% \text { ) } \\
\text { Haematocrit ( \%) } \\
\text { Work history } \\
\text { Most cigarettes smoked } \\
\text { History of peptic ulcer } \\
\text { History of diabetes }\end{array}$ & $\begin{array}{l}50 \cdot 4 \\
171 \cdot 5 \\
77 \cdot 9 \\
96 \cdot 7 \\
29 \cdot 1 \\
31 \cdot 6 \\
10 \cdot 2 \\
20 \cdot 7 \\
132 \cdot 7 \\
86 \cdot 2 \\
3 \cdot 03 \\
238 \cdot 4 \\
235 \cdot 8 \\
0 \cdot 256 \\
0 \cdot 179 \\
0 \cdot 538 \\
492 \cdot 3 \\
7 \cdot 33 \\
50 \cdot 3 \\
27 \cdot 7 \\
1 \cdot 54 \\
0 \cdot 128 \\
0 \cdot 333\end{array}$ & $\begin{array}{c}49 \cdot 3 \\
171 \cdot 7 \\
73 \cdot 1 \\
90 \cdot 1 \\
28 \cdot 3 \\
32 \cdot 4 \\
10 \cdot 2 \\
21 \cdot 1 \\
138 \cdot 8 \\
91 \cdot 3 \\
1 \cdot 34 \\
220 \cdot 8 \\
188 \cdot 3 \\
0 \cdot 108 \\
0 \cdot 060 \\
0 \cdot 313 \\
489 \cdot 0 \\
0 \cdot 036 \\
49 \cdot 6 \\
26 \cdot 7 \\
1 \cdot 22 \\
0 \cdot 241 \\
0 \cdot 084\end{array}$ & $\begin{array}{c}53 \cdot 5 \\
162 \cdot 8 \\
61 \cdot 9 \\
71 \cdot 9 \\
26 \cdot 1 \\
29 \cdot 4 \\
8 \cdot 21 \\
15 \cdot 6 \\
137 \cdot 9 \\
85 \cdot 0 \\
2 \cdot 57 \\
252 \cdot 2 \\
172 \cdot 6 \\
0 \cdot 149 \\
0 \cdot 104 \\
0 \cdot 373 \\
488 \cdot 4 \\
7 \cdot 84 \\
49 \cdot 3 \\
23 \cdot 4 \\
1 \cdot 60 \\
0 \cdot 418 \\
0 \cdot 104\end{array}$ & $\begin{array}{c}53 \cdot 2 \\
164 \cdot 1 \\
59 \cdot 6 \\
68 \cdot 9 \\
26.9 \\
28 \cdot 9 \\
7 \cdot 85 \\
14 \cdot 6 \\
131 \cdot 2 \\
82 \cdot 2 \\
0.90 \\
223 \cdot 6 \\
183.5 \\
0.088 \\
0.059 \\
0.132 \\
487.1 \\
1.19 \\
48.7 \\
25.1 \\
1.30 \\
0.279 \\
0.081\end{array}$ & $\begin{array}{c}52 \cdot 4 \\
166 \cdot 1 \\
67 \cdot 8 \\
81 \cdot 0 \\
27 \cdot 2 \\
30 \cdot 2 \\
8 \cdot 94 \\
17 \cdot 5 \\
136 \cdot 0 \\
85 \cdot 4 \\
2 \cdot 74 \\
247 \cdot 1 \\
195 \cdot 9 \\
0 \cdot 188 \\
0 \cdot 132 \\
0 \cdot 434 \\
489 \cdot 8 \\
7 \cdot 65 \\
49 \cdot 7 \\
25 \cdot 0 \\
1 \cdot 58 \\
0 \cdot 311 \\
0 \cdot 188\end{array}$ & $\begin{array}{c}51 \cdot 7 \\
166 \cdot 9 \\
64 \cdot 7 \\
76 \cdot 9 \\
27 \cdot 4 \\
30 \cdot 2 \\
8 \cdot 74 \\
17 \cdot 1 \\
134 \cdot 1 \\
85 \cdot 8 \\
1 \cdot 07 \\
222 \cdot 5 \\
185 \cdot 3 \\
0 \cdot 096 \\
0 \cdot 059 \\
0 \cdot 201 \\
487 \cdot 8 \\
0.75 \\
49 \cdot 0 \\
25 \cdot 7 \\
1 \cdot 27 \\
0 \cdot 265 \\
0 \cdot 082\end{array}$ \\
\hline No. of observations & 39 & 83 & 67 & 136 & 106 & 219 \\
\hline
\end{tabular}


TABLE IV

DISCRIMINATIONS BETWEEN CASE AND CONTROL GROUPS BY RACE

\begin{tabular}{|c|c|c|c|c|c|c|}
\hline & \multicolumn{2}{|c|}{ Hawaiian } & \multicolumn{2}{|c|}{ Japanese } & \multicolumn{2}{|c|}{ All Races } \\
\hline & Stepwise & 'Forced' & Stepwise & 'Forced' & Stepwise & 'Forced' \\
\hline $\begin{array}{l}\text { Age } \\
\text { Height } \\
\text { Weight at age } 25 \\
\text { Most weight } \\
\text { Bi-iliac diameter } \\
\text { U. arm circum. } \\
\text { R. u. arm skinfold } \\
\text { R. subscap. skinfold } \\
\text { Systolic B P } \\
\text { Diastolic B P }\end{array}$ & $\begin{array}{c}= \\
= \\
= \\
= \\
-0.0075 \pm 0.0021 \star \star\end{array}$ & $\begin{array}{l}E \\
z \\
z \\
z \\
z \\
-\end{array}$ & $\begin{array}{l}E \\
z \\
z \\
z \\
z\end{array}$ & $\begin{array}{l}z \\
z \\
z \\
z \\
z\end{array}$ & $\begin{array}{c}- \\
= \\
= \\
= \\
= \\
-0.0055 \pm 0.0021 \star\end{array}$ & $\begin{array}{l}E \\
z \\
z \\
z \\
z\end{array}$ \\
\hline $\begin{array}{l}\text { Left ventricular hyper- } \\
\text { trophy } \\
\text { Cholesterol } \\
\text { Triglyceride } \\
\text { Parent CV history } \\
\text { Sib CV history }\end{array}$ & 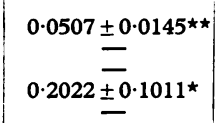 & $\mid \begin{array}{l}0.0399 \pm 0.0147 \star \star \\
0.0011 \pm 0.0007 \\
0.2190 \pm 0.1053\end{array}$ & $\begin{array}{c}0.0459 \pm 0.0124^{\star \star} \\
0.0026 \pm 0.0007^{\star \star} \\
= \\
=\end{array}$ & $\begin{array}{l}0.0458 \pm 0.0125^{\star \star} \\
0.0026 \pm 0.0007^{\star \star} \\
0.0513 \pm 0.0976\end{array}$ & $\begin{array}{c}0.0495 \pm 0.0094^{\star \star} \\
0.0020 \pm 0.0005^{\star \star} \\
=\end{array}$ & $\begin{array}{l}0.0457 \pm 0.0095^{\star \star} \\
0.0019 \pm 0.0005^{\star \star} \\
0.1311 \pm 0.0719\end{array}$ \\
\hline $\begin{array}{l}\text { History of hypertension } \\
\text { Peak flow rate } \\
\text { Heart size deviation } \\
\text { Haematocrit } \\
\text { Work history } \\
\text { Most cigarettes smoked } \\
\text { History of peptic ulcer }\end{array}$ & $\begin{array}{c}0.2277 \pm 0.0813^{\star \star} \\
= \\
- \\
=\end{array}$ & $\begin{array}{c}0.1206 \pm 0.0812 \\
= \\
= \\
=\end{array}$ & $\begin{array}{c}0.2246 \pm 0.0751 \star \star \\
= \\
= \\
=\end{array}$ & $\begin{array}{c}0.2188 \pm 0.0762^{\star \star} \\
= \\
= \\
=\end{array}$ & $\begin{array}{c}0.2253 \pm 0.0583 \star \star \\
= \\
= \\
0.0916 \pm 0.0281 \star \star\end{array}$ & $\begin{array}{c}0.1634 \pm 0.0558^{\star \star} \\
= \\
= \\
=\end{array}$ \\
\hline $\mathbf{R}^{2}$ & $\begin{array}{c}0.2987 \pm 0 \cdot 1004^{\star \star} \\
0.287\end{array}$ & $\begin{array}{c}0.3261 \pm 0.1041 \star \star \\
0.228\end{array}$ & $\overline{0} \overline{204}$ & $\begin{array}{c}0.0193 \pm 0.1062 \\
0.206\end{array}$ & $\begin{array}{c}0.1663 \pm 0.0731^{\star} \\
0.231\end{array}$ & $\begin{array}{c}0.1688 \pm 0.0746 \star \\
0.192\end{array}$ \\
\hline $\begin{array}{l}\text { Total no. of cases } \\
\text { Total no. of controls }\end{array}$ & $\begin{array}{l}39 \\
83\end{array}$ & $\begin{array}{l}39 \\
83\end{array}$ & $\begin{array}{r}67 \\
136\end{array}$ & $\begin{array}{r}67 \\
136\end{array}$ & $\begin{array}{l}106 \\
219\end{array}$ & $\begin{array}{l}106 \\
219\end{array}$ \\
\hline Intercept & 1.076 & -0.138 & -0.383 & -0.384 & 0.056 & -0.264 \\
\hline
\end{tabular}

$\star \mathrm{p} \leq 0.05 . \quad \star \star \star \mathrm{p} \leq 0.01$

measurement of heart size deviation apparently does not contribute additional information to the discrimination.

Other significant variables are not repeated in both races. The Hawaiian cases showed reduced systolic blood pressure in comparison with its control group. This is puzzling. It is not, however, reflected in the Japanese group. It is of interest to note that the Hawaiian controls have somewhat higher systolic and diastolic blood pressure to begin with than the Japanese. In fact, the Hawaiian controls have slightly higher blood pressure of both types than do the Japanese cases (Table III). However, the fact that in both racial groups the cases showed clearly higher frequency of positive history of hypertension supports the hypothesis that the lowered blood pressure of the Hawaiian cases is probably an artefact unrelated to the inherent risk. This problem will be discussed further presently.

Other significant variables for the Hawaiian group pertain to other disease histories of the subjects involved or family history of the subjects. Thus, the Hawaiian cases could be differentiated from the controls by higher frequency of positive history of diabetes in the subjects studied and by an increased degree of involvement in apparent cardiovascular disease on the part of their parents.

The Japanese cases showed a distinct increase over the controls in the level of cholesterol (case mean $=252.2 \mathrm{mg} . / 100 \mathrm{ml}$, control mean $=223.6$ $\mathrm{mg}$. $/ 100 \mathrm{ml}$.) whereas the difference was not significant in the Hawaiian group (case mean $=238.4 \mathrm{mg}$./ $100 \mathrm{ml}$., control mean $=220.8 \mathrm{mg} . / 100 \mathrm{ml}$.) as analysed by the present method.

It is of great interest to note that none of the seven anthropometric measurements have been found to be significant in the discrimination when other putative precursor factors such as cholesterol and history of hypertension were included in the model. This suggests that the effect of anthropometric measurements, if any, on the risk of the heart disease may be at best indirect. This hypothesis is consistent with a recent finding that body weight and skinfold thickness were distinctly related to existing blood pressure and subsequent development of hypertension (Kannel et al., 1967a).

Analysis of heterogeneity of the coefficients of the discriminant function is given in Table V. The set of variables includes only those factors that were found significant in the discriminant analysis for Hawaiians and/or Japanese groups with the exception of systolic blood pressure. This group of variables is designated as 'forced' in the Table. The basis for the elimination of the blood pressure from the model has been discussed previously. The coefficients common to the two racial groups involving the five variables of interest based on the intraracial variation is also given in the last column 
of Table IV ('forced'). There is no evidence that the two sets of coefficients are heterogeneous as seen by $F=1.76$ with degrees of freedom 5 and 313 (Table V).

TABLE V

TESTS OF HETEROGENEITY OF PARTIAL REGRESSION COEFFICIENTS

\begin{tabular}{l|c|c|c|c|c}
\hline & \multicolumn{2}{|c|}{ S.S. } & \multicolumn{2}{c|}{ D.F. } & F \\
\cline { 2 - 5 } & Reg. & Resid. & Reg. & Resid. & \\
\hline Hawaiian & 6.0368 & 20.4960 & 5 & 116 & - \\
Japanese & $9 \cdot 2183$ & 35.6684 & 5 & 197 & - \\
$\begin{array}{l}\text { Within Hawaiian and } \\
\text { within Japanese }\end{array}$ & 13.6807 & 57.7388 & 5 & 318 & 1.76 \\
Hawaiian and Japanese & $15 \cdot 2551$ & 56.1644 & 10 & 313 & - \\
\hline
\end{tabular}

$$
F=\frac{57 \cdot 7388-56 \cdot 1644}{5} \div \frac{56 \cdot 1644}{313}=1 \cdot 76(5,313)
$$

The stepwise regression analysis of both racial groups based on the single intraracial sum of squares matrix reveals another significant association between the coronary heart disease risk and the greatest number of cigarettes smoked at the expense of history of parental cardiovascular disease which was included in the model above (Table IV). From this it appears that both of these factors are of borderline significance in our data.

However, blood pressure still shows a confusing picture; slightly lower diastolic blood pressure in the cases appears to be discriminatory. Because of its dubious value in a predictive sense, this variable was eliminated from further consideration. Thus, the final common discriminant function includes left ventricular hypertrophy, cholesterol, history of hypertension, and most cigarettes smoked. The equation is $d=0.0467 \mathrm{~L}+0.0019 \mathrm{Ch}+0.1874 \mathrm{D}+$ $0 \cdot 1701 \mathrm{H}+0 \cdot 1001 \mathrm{C}$, where $\mathrm{L}, \mathrm{Ch}, \mathrm{D}, \mathrm{H}$, and $\mathrm{C}$ represent left ventricular hypertrophy, cholesterol, history of diabetes, history of hypertension, and most cigarettes smoked, respectively. The multiple correlation squared $\left(\mathbf{R}^{2}\right)$ for these factors amounts to $0 \cdot 214$.

The distribution of the discriminant scores based on the above equation for the case and control groups are given in the Figure separately for the Hawaiians and Japanese. The shapes of the distributions of the scores are similar for the two racial groups whether in the cases or the controls, though the distribution of the scores of the Hawaiian controls appears more skewed to the right than the counterpart of the Japanese. The mean scores for the case groups are $0.892 \pm 0.149$ and $0.831 \pm 0.105$ for the Hawaiians and the Japanese, respectively, whereas those for the respective control groups are $0.663 \pm$ 0.076 and $0.626 \pm 0.056$, indicating that Hawaiians are in general at higher risk, though none of these differences are significant.

It is interesting to observe that the distributions of the scores of the cases tend to be bimodal in both races, though this is more marked in the Japanese group with a larger number of observations. That part of distribution with lower mode (lower risk) tends to follow that of the controls; and the mode of
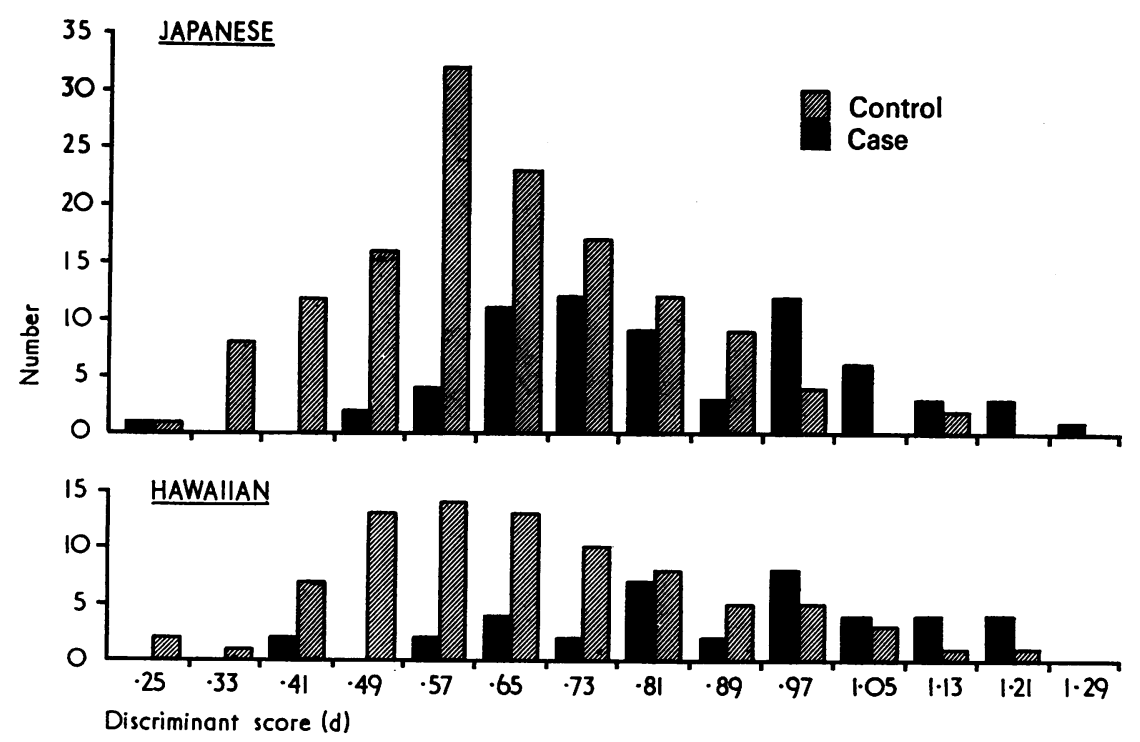

FIG. Distributions of discriminant scores by race. 
the remaining distribution is found in the interval of 0.93-1.00. The latter fraction with the higher mode (high risk) accounts for $51.3 \%$ and $37.3 \%$ of the cases for Hawaiians and Japanese, respectively, if we take the score of 0.93 as the dividing point. However, the absence of any specific factors associated with the secondary mode in the two racial groups coupled with the relatively small size of samples involved in the study suggests that the apparent bimodality can be attributed to sampling error (see Murphy, 1964).

\section{Discussion}

This investigation is a retrospective study on putative risk factors of coronary heart disease. As such, it is recognized that there are certain limitations if the data were to be used for the predictive purpose for the coronary heart disease risk. The limitations would be of two types. A given variable may be attributed as a 'risk factor' erroneously if the presence or elevation of the factor was observed only after myocardial infarction. On the other hand, it is possible that the expression of true coronary heart disease risk factors may have changed or disappeared at the post-myocardial infarction examination of survivors. It is, however, comforting to note that our data are in general agreement with a larger prospective study (Dawber, 1963; Kagan et al., 1963).

The fact that the Hawaiian cases showed lower blood pressure levels (systolic and diastolic) than the controls is in direct contrast to what is known about the association between this factor and the risk of developing coronary heart disease. There are three possible explanations: (1) treatment effect, (2) effect of myocardial infarction on blood pressure, and (3) post-myocardial infarction survival associated with hypertension. The first two explanations appear tenuous, since on this hypothesis we must assume that the Hawaiian cases responded to treatment or myocardial infarction differently from the Japanese patients. At present we cannot rule out the possible presence of the type of interaction involving race. But it is more tempting to hypothesize that the probability of survival after myocardial infarction would depend on blood pressure of the patients (i.e. higher mortality rate for patients with higher blood pressure), and that higher rate of mortality due to myocardial infarction for Hawaiians may have led to the observed result. Moellering and Bassett (1967) have shown that the death rate for Hawaiians of acute myocardial infarct cases (in hospital) was nearly double that of the Japanese. Whatever the reason is for the discrepant result of the present blood pressure, it is important to remember that previous history of hypertension is clearly related to increased risk of coronary heart disease in both racial groups.

The positive relation between left ventricular hypertrophy and the risk found corroborates the finding of the Framingham study (Kagan et al., 1963), though it is possible that our study might exaggerate the association because of the possible \& effect of myocardial infarction on left ventricular $\vec{\circ}$ hypertrophy. Increased positive history of cardiovascular disease found among the parents of the cases is consistent with other data (Gertler et al., 1959; Thomas and Ross, 1964; Slack and Evans, 1966). It is not, however, known to what extent the familial trend reflects genetic variation. It is $\overrightarrow{0}$ possible that the familial tendency to cardiovascular 6 disease may be mediated through a genetic pre- 은 disposition to diabetes mellitus, whose effect as a coronary heart disease risk factor has been shown to be significant in our study. Elucidation of this point requires consideration of the family history of diabetes.

It is unquestionable that the level of cholesterol has a significant value in the discrimination of high and low risk individuals; this is supported by numerous studies on coronary heart disease, both prospective and retrospective. History of diabetes has been shown to be strongly discriminatory between the cases and controls, more so in the Hawaiian group. One-third of the Hawaiian cases reported a history of diabetes mellitus, whereas only $8 \%$ of the controls had this history. While increased risk for coronary heart disease due to the presence of diabetes has been frequently claimed, it has only recently been shown that the association of diabetes and the coronary heart disease risk might represent part of a more general relation between deviant carbohydrate metabolism and cardiovascular disease (Epstein, 1967). Ostrander et al. (1965) found a significant association between coronary disease and hyperglycaemia with or without clinical diabetes.

The relation between hyperglyceridaemia and coronary heart disease is not clearly known at present (Epstein, 1967). When we considered concentration of fasting serum triglyceride simultaneously with cholesterol concentration and history of diabetes besides other variables, triglyceride was not found to contribute any additional information to the discrimination between the case and control groups. It is known that carbohydrate intake induces hyperglyceridaemia (Ahrens et al., 1961; Kuo and Bassett, 1965). Thus, it is possible that hyperglyceridaemia is closely related to abnormal carbohydrate metabolism, an extreme form of which is 
diabetes mellitus. On this hypothesis it is not surprising that we have not detected any association between the level of triglyceride and coronary heart disease independent of history of diabetes.

For the two racial groups combined, the discriminatory factors found significant are left ventricular hypertrophy, cholesterol, history of hypertension, smoking history, and history of diabetes, if we ignore the aberrant blood pressure association. All of these are variables that have been implicated as risk factors in larger epidemiological studies (Dawber, 1963; Kagan et al., 1963; Epstein et al., 1965). Admittedly the power of the discriminant function involving these variables is not high as seen by the multiple correlation squared $\left(R^{2}=0.214\right)$ and the overlapping distributions of the discriminant scores. It is, therefore, expected that prediction based on the function is not expected to be very reliable, but the procedure will provide an objective way of classifying individuals with respect to the risk for coronary heart disease.

Inclusion of all 23 possible risk variables in the model does not improve the power of discrimination substantially $\left(R^{2}=0 \cdot 288\right)$. Thus, it can be said that we are successful in reducing a large number of putative risk factors to a small number of essential variables whose relationships to coronary heart disease are largely independent of each other. As pointed out earlier, none of the anthropometric traits was shown to make independent contribution to the discrimination. It should be noted that such measurements as weight at age 25 , height, and most weight attained are presumably free of any bias due to past myocardial infarction per se, but our data could have been influenced by possible differential mortality rate relative to weight as claimed by Kannel et al. (1967b). Other factors including sib history of cardiovascular disease, vital capacity measured by peak flow rate, heart size deviation, haematocrit, work history, and history of peptic ulcer have yielded no additional information in distinguishing low from high risk subjects for coronary heart disease in our data.

One of the critical questions raised in this study was whether or not risk factors, if found significant, were homogeneous in their relations with coronary heart disease in Hawaiians and Japanese. When the five factors, which include left ventricular hypertrophy, cholesterol, histories of hypertension, diabetes, and parental cardiovascular disease, were considered together, there was no evidence to indicate that these factors were exerting their influences differently in the two racial groups. However, the failure to detect heterogeneity does not mean that the average risk of Hawaiians is the same as that of
Japanese. The Hawaiians were shown to have higher average risk scores than the Japanese, both in cases and controls. To a degree the increased risk is related to higher frequency of diabetes among Hawaiians. When diabetes was not considered in the discrimination, the mean discriminant scores were $0.830 \pm 0.138$ and $0.812 \pm 0.103$ for the Hawaiian and Japanese case groups, respectively. The mean difference in the score was 0.018 compared with 0.061 when the variable was included in the model. However, the elimination of diabetes from the discriminant function had little effect on the mean difference in the score in the control groups.

\section{Summary}

Discriminant analyses have been performed on 23 putative risk factors for 39 coronary heart disease patients and 83 controls of Hawaiians and 67 patients and 136 controls of Japanese residing in Hawaii.

The minimum set of discriminant variables, which accounts for nearly all variation between the case and control groups, was left ventricular hypertrophy, and positive histories of hypertension, diabetes, and parental cardiovascular disease for Hawaiians, whereas the set for Japanese included left ventricular hypertrophy, cholesterol, and history of hypertension. The available records on left ventricular hypertrophy and history of hypertension were apparently complementary in the data. There was no indication that the relationships of these factors with the risk of coronary heart disease were heterogeneous between the two racial groups.

\section{REFERENCES}

Ahrens, E. H., Jr., Hirsch, J., Oette, K., Farquhar, J. W., and Stein, Y. (1961). Carbohydrate-induced and fat-induced lipemia. Trans. Ass. Amer. Phycns, 74, 134.

Bassett, D. R.. Moellering, R. C., Rosenblatt, G., Greenberg, D., and Stokes, J., III (1968). Coronary heart disease in Hawaii: Serum lipids, and cardiovascular, anthropometric, and related findings in Japanese and Hawaiian men. 7 . chron. Dis. In the press.

Bennett, C. G., Tokuyama, G. H., and McBride, T. C. (1962). Cardiovascular-renal mortality in Hawaii. Amer. F. Publ. Hlth, 52, 1418.

Chung, C. S., and Morton, N. E. (1959). Discrimination of genetic entities in muscular dystrophy. Amer. F. hum. Genet., 11, 339.

Dawber, T. R. (1963). Coronary heart disease. Morbidity in the Framingham study and analysis of factors of risk. Bibl. cardiol. (Basel), 13, 9.

Epstein, F. H. (1967). Hyperglycemia: a risk factor in coronary heart disease. Circulation, 36, 609.

- Ostrander, L. D., Johnson, B. C., Payne, M. W., Hayner, N. S., Keller, J. B., and Francis, T. (1965). Epidemiological studies of cardiovascular disease in a total community-Tecumseh, Michigan. Ann. intern. Med., 62, 1170.

Fisher, R. A. (1938). The statistical utilization of multiple measurements. Ann. Eugen. (Lond.), 8, 376.

Gertler, M. M., Woodbury, M. A., Gottsch, L. G., White, P. D., and Rusk, H. A. (1959). The candidate for coronary heart disease. Discriminating power of biochemical hereditary and anthropometric measurements. F. Amer. med. Ass., 170, 149. 
Kagan, A., Kannel, W. B., Dawber, T. R., and Revotskie, N. (1963). The coronary profile. Ann. N. Y. Acad. Sci., 97, 883.

Kannel, W. B., Brand, N., Skinner, J. J., Jr., Dawber, T. R., and McNamara, P. M. (1967a). The relation of adiposity to blood pressure and development of hypertension. The Framingham study. Ann. intern. Med., 67, 48.

- LeBauer, E. J., Dawber, T. R., and McNamara, P. M. (1967b). Relation of body weight to development of coronary heart disease. The Framingham study. Circulation, 35, 734.

Kuo, P. T., and Bassett, D. R. (1965). Dietary sugar in the production of hyperglyceridemia. Ann. intern. Med., 62, 1199.

Moellering, R. C., and Bassett, D. R. (1967). Myocardial infarction in Hawaiian and Japanese males on Oahu-A review of 505 cases occurring between 1955 and 1964 . F. chron. Dis., $20,89$.

Morris, J. N., Kagan, A., Pattison, D. C., Gardner, M. J., and Raffle, P. A. B. (1966). Incidence and prediction of ischaemic heartdisease in London busmen. Lancet, 2, 553.
Murphy, E. A. (1964). One cause? Many causes? The argu-D ment from the bimodal distribution. $f$. chron. Dis., 17, 301.

Ostrander, L. D., Francis, T., Hayner, N. S., Kjelberg, M. O., and Epstein, F. H. (1965). The relationship of cardiovascular disease to hyperglycemia. Ann. intern. Med., 62, 1188.

Rao, C. R. (1952). Advanced Statistical Methods in Biometric Research. Wiley and Sons, New York.

Slack, J., and Evans, K. A. (1966). The increased risk of death fromo ischaemic heart disease in first degree relatives of 121 men and $96 \overline{\bar{c}}$ women with ischaemic heart disease. $f$. med. Genet., 3, 239.

Thomas, C. B., and Ross, D. C. (1964). The heritage of hyper- $D$ tension and coronary disease: discriminant function analysis of the characteristics of healthy young adults. Amer. F. Med. Sci., 248, 505.

Truett, J., Cornfield, J., and Kannel, W. (1967). A multivariate. analysis of the risk of coronary heart disease in Framingham. $\mathcal{F} . \overrightarrow{\mathrm{C}}$ chron. Dis., 20, 511. 